\title{
Journal of Biomechanics
}

\section{Concurrent validity and reliability of the mobile Steam®VR tracking technology, using sensors to measure movements of the neck

\author{
--Manuscript Draft--
}

\begin{tabular}{|c|c|}
\hline Manuscript Number: & \\
\hline Article Type: & Short Communication (max 2000 words) \\
\hline Keywords: & $\begin{array}{l}\text { Concurrent validity } \\
\text { Reliability } \\
\text { Neck } \\
\text { Motion capturing } \\
\text { Steam®VR tracking technology }\end{array}$ \\
\hline Corresponding Author: & $\begin{array}{l}\text { Bettina B. Sommer, MSc } \\
\text { Zurich University of Applied Sciences } \\
\text { Winterthur, SWITZERLAND }\end{array}$ \\
\hline First Author: & Bettina B. Sommer \\
\hline Order of Authors: & Bettina B. Sommer \\
\hline & Martin Weisenhorn \\
\hline & Markus J. Ernst \\
\hline & André Meichtry \\
\hline & Fabian M. Rast \\
\hline & Dominik Kleger \\
\hline & Philipp Schmid \\
\hline & Lars Lünenburger \\
\hline & Christoph M. Bauer \\
\hline Abstract: & $\begin{array}{l}\text { The neck can be moved in six degrees of freedom. Current motion-capture systems } \\
\text { capable of measuring these movements are inappropriate for use in clinical practice } \\
\text { because they are stationary, expensive and time-consuming. We therefore developed } \\
\text { a less complex prototype system to measure six degrees of freedom in a clinical } \\
\text { setting. The aim of this study was to assess the validity and reliability of this } \\
\text { system. The developed prototype consists of two infrared-emitting lighthouses and } \\
\text { sensors, mounted on the participant's helmet and trunk belt, to detect the orientation of } \\
\text { the head and trunk. The system was evaluated by means of an infrared light-reflecting } \\
\text { marker tracking system. Twenty healthy participants, equipped with these sensors and } \\
\text { markers, performed thirteen neck movement tasks. Linear and angular movements } \\
\text { were measured. These tasks were repeated after six to eight days to assess test-retest } \\
\text { reliability. Concurrent validity was assessed by the root mean square error, and } \\
\text { reliability with generalizability theory.With an average root mean square error between } \\
1.2-2.0^{\circ} \text { in angular and } 0.4-0.5 \text { cm in linear movements, the prototype was shown to } \\
\text { precisely track these movements. Reliability of the prototype and the reference system } \\
\text { was comparable for all tasks. A high contribution of participant's variability to the } \\
\text { observed variance was generally detected, with the except of joint repositioning error } \\
\text { and upper cervical flexion. The reliability was task-specific and did not differ between } \\
\text { the systems. The prototype system was shown to be valid, although the reliability of the } \\
\text { repositioning and upper cervical flexion tests needs to be reconsidered. }\end{array}$ \\
\hline
\end{tabular}


1 Concurrent validity and reliability of the mobile Steam ${ }^{\circledR}$ RR tracking technology, using

2 sensors to measure movements of the neck

3

4 Short communication

5

6 Bettina B. Sommer ${ }^{1}$

7 Martin Weisenhorn²

8 Markus J. Ernst ${ }^{1}$

9 André Meichtry ${ }^{1}$

10 Fabian M. Rast ${ }^{1}$

11 Dominik Kleger²

12 Philipp Schmid ${ }^{2}$

13 Lars Lünenburger ${ }^{3}$

14 Christoph M. Bauer ${ }^{1}$

${ }^{1}$ Zurich University of Applied Sciences, School of Health Professions, Institute of Physiotherapy, Winterthur, Switzerland

${ }^{2}$ Zurich University of Applied Sciences, School of Engineering, Institute of Signal Processing and Wireless Communications, Winterthur, Switzerland

${ }^{3}$ Hocoma AG, Volketswil, Switzerland

Corresponding author:

Bettina Sommer, Technikumstrasse 71, P.O. Box, CH-8401 Winterthur, Switzerland

Tel: +415893463 30

Fax: +41589356330

E-mail: bettina.sommer@zhaw.ch

Wordcount: Abstract 250, Main text 1999 


\section{Abstract}

The neck can be moved in six degrees of freedom. Current motion-capture systems capable of measuring these movements are inappropriate for use in clinical practice because they are stationary, expensive and time-consuming. We therefore developed a less complex prototype system to measure six degrees of freedom in a clinical setting. The aim of this study was to assess the validity and reliability of this system.

The developed prototype consists of two infrared-emitting lighthouses and sensors, mounted on the participant's helmet and trunk belt, to detect the orientation of the head and trunk. The system was evaluated by means of an infrared light-reflecting marker tracking system. Twenty healthy participants, equipped with these sensors and markers, performed thirteen neck movement tasks. Linear and angular movements were measured. These tasks were repeated after six to eight days to assess test-retest reliability. Concurrent validity was assessed by the root mean square error, and reliability with generalizability theory. With an average root mean square error between $1.2-2.0^{\circ}$ in angular and $0.4-0.5 \mathrm{~cm}$ in linear movements, the prototype was shown to precisely track these movements. Reliability of the prototype and the reference system was comparable for all tasks. A high contribution of participant's variability to the observed variance was generally detected, with the except of joint repositioning error and upper cervical flexion.

The reliability was task-specific and did not differ between the systems. The prototype system was shown to be valid, although the reliability of the repositioning and upper cervical flexion tests needs to be reconsidered. 


\section{Introduction}

The anatomical and physiological characteristics of the cervical spine allow humans to rotate and translate their head relative to the thorax in all directions (six degrees of freedom) (Ordway et al., 1997; Park, 2015; Seo et al., 2013). Impairment of the neck is related to the cervical range of motion (Ernst et al., 2015; Hall et al., 2010). Clinical tests of global cervical range of motion are frequently used in clinics (Childs et al., 2008). These tests are valid and reliable (Audette et al., 2010) but lack the ability to record data during neck movement and to provide patient feedback.

Modern marker-based motion capture systems can accurately measure movement in six degrees of freedom, but they are time-consuming, expensive, stationary and inappropriate for clinical practice. Smaller inertial measurement units are used in clinical settings to track orientation, although they are prone to error when deriving translation, which frequently occurs for cervical movements (Wang et al., 2010). Therefore, we developed a prototype to measure both linear and angular displacement that is more appropriate to the clinical setting in contrast to the system investigated in Niehorster et al., 2017. The aim of this study was to assess the concurrent validity and reliability of this prototype.

\section{Methods}

\subsection{Participants:}

Thirteen healthy female and seven healthy male participants (Table 1) were recruited amongst a university staff and students. Participants were free of acute or chronic diseases, had not previously undergone spinal surgery, were not taking perception-influencing drugs and measured less than five points on the Neck Disability Index (an indicator of no disability) (Vernon, 2008). The local ethics committee juristically verified the study and participants signed an informed consent form.

2.2 Data collection and analysis 
System under test (SUT). Angular and linear movements of head and trunk were measured using in-house developed trackers. The tracking principle followed the Steam ${ }^{\circledR}$ VR-Tracking technology, which is distributed by $\mathrm{HTC}^{\circledR}$ as part of a virtual-reality system. Our SUT consisted of two HTC laser-emitting lighthouses combined with two trackers for tracking head and trunk motion. The trackers were comprised of multiple sensor boards, each equipped with four infrared light detectors geometrically arranged to guarantee a line-of-sight from the lighthouses to at least one of the sensor boards (Figure 1). Both trackers were also equipped with an individual controller board to capture the time instants of a laser imaging on one of the light detectors. These time instants were communicated via Bluetooth to a computer that computed the positions and orientations at a rate of $30 \mathrm{~Hz}$. The poses signaled by the SUT were represented as relative poses of the upper front board of the helmet $\left(T_{F}\right)$ and the right-side board of the belt $\left(T_{T}\right)$ relative to the lighthouse coordinate system (Figure 1).

Reference System. The $\mathrm{VICON}^{\circledR}$ motion capture system (Vicon Motion Systems, Oxford, UK) was employed to compare and assess the validity of the SUT. This system was comprised of twelve infrared cameras combined with reflecting markers on the back of the helmet, on the right-side board of the belt and, during the static measurement, on the front of the helmet. The marker coordinates were sampled at $120 \mathrm{~Hz}$ and expressed with respect to the movement laboratory specific coordinate system. Data were then downsampled to $30 \mathrm{~Hz}$. The pose of Vicon back of the head $\left(T_{B}\right)$ to forehead $\left(T_{F}\right)$ was determined through a static measurement. The forehead markers were then removed to allow better visibility of the sensor boards.

Comparison of Measurements. To compare the poses resulting from the two systems, they were expressed in the same coordinate system. The relative pose of the coordinate systems was calculated on the basis of the static measurement. The poses obtained from the Vicon system were expressed with respect to the SUT coordinate system. The reference coordinate System $\left(T_{R}\right)$ was aligned with the movement in sagittal, frontal and transverse 
planes. To achieve this, the coordinate system of the trunk $\left(T_{T}\right)$ was transformed with

$\mathrm{T}_{\mathrm{T}}^{\mathrm{R}}=\left[\begin{array}{cccc}\cos \alpha & 0 & -\sin \alpha & t x \\ 0 & 1 & 0 & 0 \\ \sin \alpha & 0 & \cos \alpha & t z \\ 0 & 0 & 0 & 1\end{array}\right]$

with its origin between the two belt-fixed sensors in front of the sternum (Figure 1, right

bottom). The forehead coordinate system had its origin on the middle of the upper front sensor on the helmet $\left(T_{F}\right)$. Movement between head and trunk was expressed as the pose

$121 T_{T}^{F}$.

$T_{T}^{F}=T_{R}^{F}\left(T_{R}^{T}\right)^{-1}$

$T_{R}^{F}$ s transformation matrix from the reference to the forehead coordinate system

Outlier elimination. Both pose measurement systems occasionally provided erroneous pose samples, resulting in erroneous position as well as orientation measurements. Outliers were detected via Hampel's method (Liu et al., 2004): if a position coordinate or an orientation variable deviated more than 1.5 standard deviations from the median of the recent 15 samples, the related pose was classified as an outlier. Outliers of both systems were detected and excluded from the analysis.

Transformation matrices were calculated for the SUT and the Vicon reference system.

Rotation was parametrized by Euler angles in the 'zyx' order, which was found to be the best choice for our application to avoid gimbal-lock. All calculations were performed with Matlab R2017a and Software R (R Core Team, 2018).

\subsection{Procedure}

Following a static measurement, each participant performed the tasks described in Table 2. Participants were seated on a chair in an upright posture during all tasks. After a practice trial, seven repetitions of the tasks were performed in randomized order at a self-defined speed. Participants took a break of five seconds between repetitions and one minute between tasks. To assess test-retest reliability, each participant repeated all the tasks some six to eight days later, in the same order and at the same time of day . 
$143 \quad$ 2.4.1 Range of motion and joint position error

144 Range of motion (ROM) was calculated for each participant's repetitions on both days (tasks 145 described in Table 2).

$146 R O M=\| \max \alpha-\min \alpha \mid$

$147 \alpha$ : measured angle in main movement direction

148 Absolute joint position error (JPE), following a rotation to the left and right sides (JPRL,

149 JPRR), was determined by the difference between rotation at the start and end of the

150 repetition (Treleaven et al., 2003). For start and end positions, 50 frames were considered,

151 since the subjects were told to hold the position for two seconds.

152

$I P E=\left|\frac{\sum_{i=1}^{i=50} \alpha_{i}}{50}-\frac{\sum_{i=n}^{i=50} \alpha_{i}}{50}\right|$

$153 n$ : number of frames

$154 \alpha_{i}$ : measured rotation angle at frame $\mathrm{i}$

$155 \quad$ 2.4.2 Root mean square error

156 The root mean square error (RMSE) was calculated between both systems as a measure of 157 concurrent validity:

RMSE $=\sqrt{\sum_{i}\left(x_{i}-y_{i}\right)^{2} / n}$

$159 x_{i}, y_{i}$ : measured position vectors of the two systems at time frame $\mathrm{i}$

$160 n$ : number of frames

161 RMSE was calculated for each repetition, participant and day in all six degrees of freedom.

162 For following the Zigzag pattern (ZIZA) (Werner et al., 2018), data of the helmet without

163 differential signal to the trunk were considered, since the trunk sensors were hidden behind 164 the pattern for lighthouse visibility. 


\subsubsection{Reliability}

Generalizability theory (G-theory) was applied to assess reliability,(Brennan, 2001). With the fully crossed participant $x$ day $x$ repetition $(p \times d \times r)$ design, the decomposition of observed score variance $\sigma_{Y}^{2}$ was given by

$\sigma_{Y}^{2}=\sigma_{p}^{2}+\sigma_{d}^{2}+\sigma_{r}^{2}+\sigma_{p d}^{2}+\sigma_{p r}^{2}+\sigma_{r d}^{2}+\sigma_{p r d}^{2}$

The universe of generalization was day and repetition. The object of measurement was participant. The universe score was the expected value of the observed scores for participant over the conditions in the universe of generalization.

Given the variance components, the index of dependability $(\Phi)$ could be computed. This index is defined as the proportion of the observed score variance that is attributable to participants variance.

$\Phi=\frac{\sigma_{p}^{2}}{\sigma_{p}^{2}+\sigma_{d}^{2}+\sigma_{r}^{2}+\sigma_{p d}^{2}+\sigma_{p r}^{2}+\sigma_{r d}^{2}+\sigma_{p r d}^{2}}$.

ROM and JPE for both systems and each repetition were used as outcomes. RMSE values were also analyzed in a second analysis.

The above mentioned $\Phi$ represents the reliability when generalized over one day and one repetition. To quantify the reliability for the mean of $k$ repetitions, i.e. generalizing over one day and an average of $\mathrm{k}$ repetitions, the quantities $\sigma_{r}^{2}, \sigma_{p r}^{2}, \sigma_{r d}^{2}$ and $\sigma_{p r d}^{2}$ were divided by $\mathrm{k}$. This decision-study then examined how many repetitions are required for an acceptable dependability $\Phi$. In this study, this was performed for $k=1,2,3, \ldots, 7$ repetitions.

The index ranges were from 0 to 1 , with $<0.4$ indicating poor, $0.4-0.75$ moderate and $>0.75$ excellent reliability (Santos et al., 2008).

Variance components were estimated with the Ime4 package of $R$ (Bates et al., 2015).

\section{Results}


Data from eighteen subjects were used in the analysis. Two were excluded due to a nonresponding sensor board.

\subsection{Range of motion and joint position error}

ROM and JPR data are presented in Table 4 and Figure 2. Although ROM and JPR showed a wide range of measured values, consistency between SUT values and Vicon was observed (Figure 3).

\subsection{Validity}

RMSE values for all tasks are presented in Table 3. Based on the mean of all tasks, the RMSE values were determined as: $1.2^{\circ}$ in lateral flexion, $1.8^{\circ}$ in rotation and $2.0^{\circ}$ in flexion / extension; as well as $0.5 \mathrm{~cm}$ in lateral-medial, $0.5 \mathrm{~cm}$ in cranial-caudal and $0.4 \mathrm{~cm}$ in anterior-posterior translation.

\subsection{Reliability}

All variance components were determined for the ROM values. SeeTable 2 for the definition of abbreviations and description of exercises. The MFLX, MEXT, MLFL, MLFR, MROL, MROR, MPRT, MRET and UCEX all showed a high relative $\sigma_{p}^{2}$, indicating that the observed variance had a high participant contribution (Table 4). UCFL showed the highest contribution from $\sigma_{p d}^{2}$. Repositioning tasks, however, showed a high percentage of $\sigma_{\text {prd }}^{2}$. Lateral flexion showed excellent reliability from one repetition. MEXT, MFLX, MPRT and MRET also showed excellent reliability after three repetitions. A moderate reliability was shown for MROL, MROR and JPRR from one repetition (Table 4).

The contributions of day, repetition, participant $\mathrm{x}$ repetition, and repetition $\mathrm{x}$ day to the total variance were negligible and are consequently not presented in the overview.

The same analysis of variance was performed for RMSE values (Table 5). Participant $x$ day had the highest contribution for most tasks.

\section{Discussion}


214 The primary aim of this study was to assess the concurrent validity and reliability of an inhouse developed tracking system (SUT), built for measuring the relative motion of the head with respect to the trunk in a clinical setting. With a RMSE of between $0.2-3.1^{\circ}$ for angular movements and $0.2-0.9 \mathrm{~cm}$ for linear movements, the SUT was shown to be able to track movements precisely.

The reliabilities of the SUT and Vicon were comparable over all tasks. Poor reliabilities were found for joint reposition error and upper cervical flexion, which were not due to measurement inaccuracy. For joint repositioning, a possible cause lies in the small range (mean $1.7^{\circ}-1.8^{\circ}$ ) detected, making it difficult to distinguish between subjects. These findings concur with other studies that show poor reliability for repositioning tasks (Jørgensen et al., 2014; Lee et al., 2006).

A ROM from retraction to protraction of $8 \mathrm{~cm}$ was found for linear movements. While some studies have reported a protraction of around $20 \mathrm{~cm}$ (Lee et al., 2005; Stemper et al., 2006), our findings are similar to the sagittal mobility of $9.1 \mathrm{~cm}$ reported by Severinsson et al., 2012 . This measurement is calculated from the signal between the trunk and head, taking the trunk belt as the reference. It was observed, however, that the advancement of the head to protraction caused the trunk board to tilt downwards through a slight movement of the trunk. This changed the coordinate system alignment and had an influence on the measured ROM. When fully extending the neck in MEXT, the helmet occasionally slid backwards.

Consequently, participants extended only as far as when the helmet stayed fixed. The setup of the hardware should therefore be reconsidered in future.

G-theory outcomes for RMSE showed a generally high contribution of $\sigma_{p d}^{2}$. This could be due to the setup of the helmet, trunk belt and lighthouses, as well as the calibration and position of the participant.

As a conclusion, the reliability of the prototype SUT was comparable to Vicon and has been shown to be valid for measuring linear movements in a clinical setting. For tasks such as joint repositioning, it's reliability must be reconsidered. 
242 Conflict of interest statement

243 The authors are not aware of any financial or personal relationships with people or

244 organizations that could have improperly influenced this work.

245

246 Acknowledgments

247 The authors would like to thank Karen Linwood for editing the language. This study was

248 funded by Innosuisse (25624.1 PFLS-LS). 


\section{Captions}

Table 1: Participants' characteristics; number of participants, mean (standard deviation) weight, height, Body Mass Index and age

Table 2: Abbreviations and exercise descriptions

Table 3: Root mean square values for all tasks and directions. UCEX: upper cervical extension, UCFL: upper cervical flexion, JPRL/JPRR: Joint position error rotation left/right, MEXT: maximal extension, MFLX: maximal flexion, MLFR/MLFL: maximal lateral flexion right/left, MPRT: maximal protraction, MRET: maximal retraction, MROL/MROR: maximal rotation left/right, ZIZA: follow the Zigzag pattern

Table 4: Range of motion and joint position error measurements with its mean and standard deviation; percentual variance components for participant $\left(\sigma_{\mathrm{p}}^{2}\right)$, participant $\mathrm{x}$ day $\left(\sigma_{\mathrm{pd}}^{2} \mathrm{~d}\right)$, and residual $\left(\sigma_{\mathrm{prd}}^{2}\right)$; Number of repetitions required to reach an index of dependability $(\Phi)>0.75$ on a single day measurement. UCEX: upper cervical extension, UCFL: upper cervical flexion, MEXT: maximal extension, MFLX: maximal flexion, MLFR/MLFL: maximal lateral flexion right/left, JPRL/JPRR: Joint position error rotation left/right, , MROL/MROR: maximal rotation left/right, MPRT: maximal protraction, MRET: maximal retraction

Table 5: Generalizability theory results for root mean square error values of each task. Percentage variance components for participant $\left(\sigma_{\mathrm{p}}^{2}\right)$, participant $x$ day $\left(\sigma_{\mathrm{pd}}^{2}\right)$, and residual $\left(\sigma_{\mathrm{prd}}^{2}\right)$; UCEX: upper cervical extension, UCFL: upper cervical flexion, JPRL/JPRR: Joint position error rotation left/right, MEXT: maximal extension, MFLX: maximal flexion, MLFR/MLFL: maximal lateral flexion right/left, MPRT: maximal protraction, MRET: maximal retraction, MROL/MROR: maximal rotation left/right, ZIZA: follow the Zigzag pattern, linear movement medio-lateral

Figure 1: Each sensor board has four IR sensors to detect lasers emitted by the lighthouses; left: sensor setup with the coordinate systems of the right-sided board of the belt $\left(T_{T}\right)$ and forehead $\left(T_{F}\right)$; right top: coordinate systems of the back of the head helmet $\left(T_{B}\right)$; right bottom: transformation of the right-sided board coordinate system $\left(T_{T}\right)$ to the reference coordinate system $\left(T_{R}\right)$ of the trunk belt with view from top

Figure 2: Range of motion measured with the Vicon and System under test (SUT) for all participants' seven test and retest repetitions.

Figure 3: Example of a maximal neck flexion measured with Vicon and SUT in six degrees of freedom 
Table 1

\begin{tabular}{|c|c|c|c|c|c|}
\hline $\begin{array}{c}\text { Female } \\
\text { Participants }\end{array}$ & $\begin{array}{c}\text { Male } \\
\text { Participants }\end{array}$ & $\begin{array}{c}\text { Weight } \\
{[\mathrm{kg}]}\end{array}$ & $\begin{array}{c}\text { Height } \\
{[\mathrm{m}]}\end{array}$ & $\begin{array}{c}\text { Body Mass } \\
\text { Index }\end{array}$ & $\begin{array}{c}\text { Age } \\
\text { [years] }\end{array}$ \\
\hline 12 & 6 & 66.6 & 1.71 & 22.8 & 36.1 \\
& & $(10.5)$ & $(0.09)$ & $(2.5)$ & $(13.1)$ \\
\hline
\end{tabular}


Figure 1
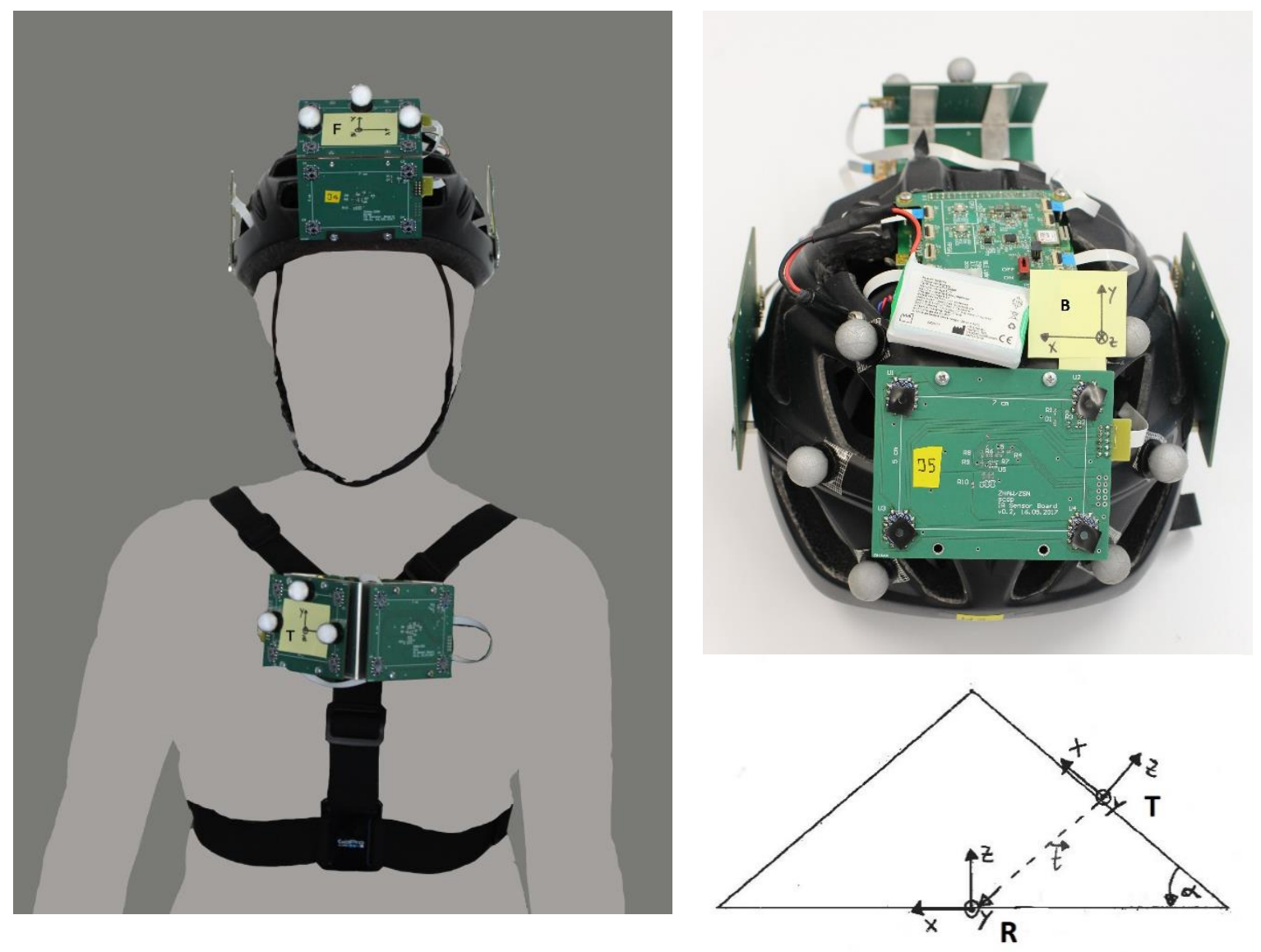
Table 2

\begin{tabular}{clc}
\hline Abbreviation & \multicolumn{1}{c}{ Exercise description } & Unit \\
\hline UCEX & Upper cervical extension & $\circ$ \\
UCFL & Upper cervical flexion & $\circ$ \\
JPRL & Joint reposition error after rotation & $\circ$ \\
& to the left \\
JPRR & Joint reposition error after rotation & $\circ$ \\
& to the right \\
MEXT & Maximal extension \\
MFLX & Maximal flexion & $\circ$ \\
MLFR & Maximal lateral flexion right & $\circ$ \\
MLFL & Maximal lateral flexion left & $\circ$ \\
MPRT & Maximal protraction & $\circ$ \\
MRET & Maximal retraction & $\mathrm{cm}$ \\
MROL & Maximal rotation left & $\mathrm{cm}$ \\
MROR & Maximal rotation right & $\circ$ \\
ZIZA & Follow a Zigzag pattern precisely, & $\circ$ \\
& rotation angle is determined & \\
\hline
\end{tabular}


Figure 2

Range of motion and joint position error
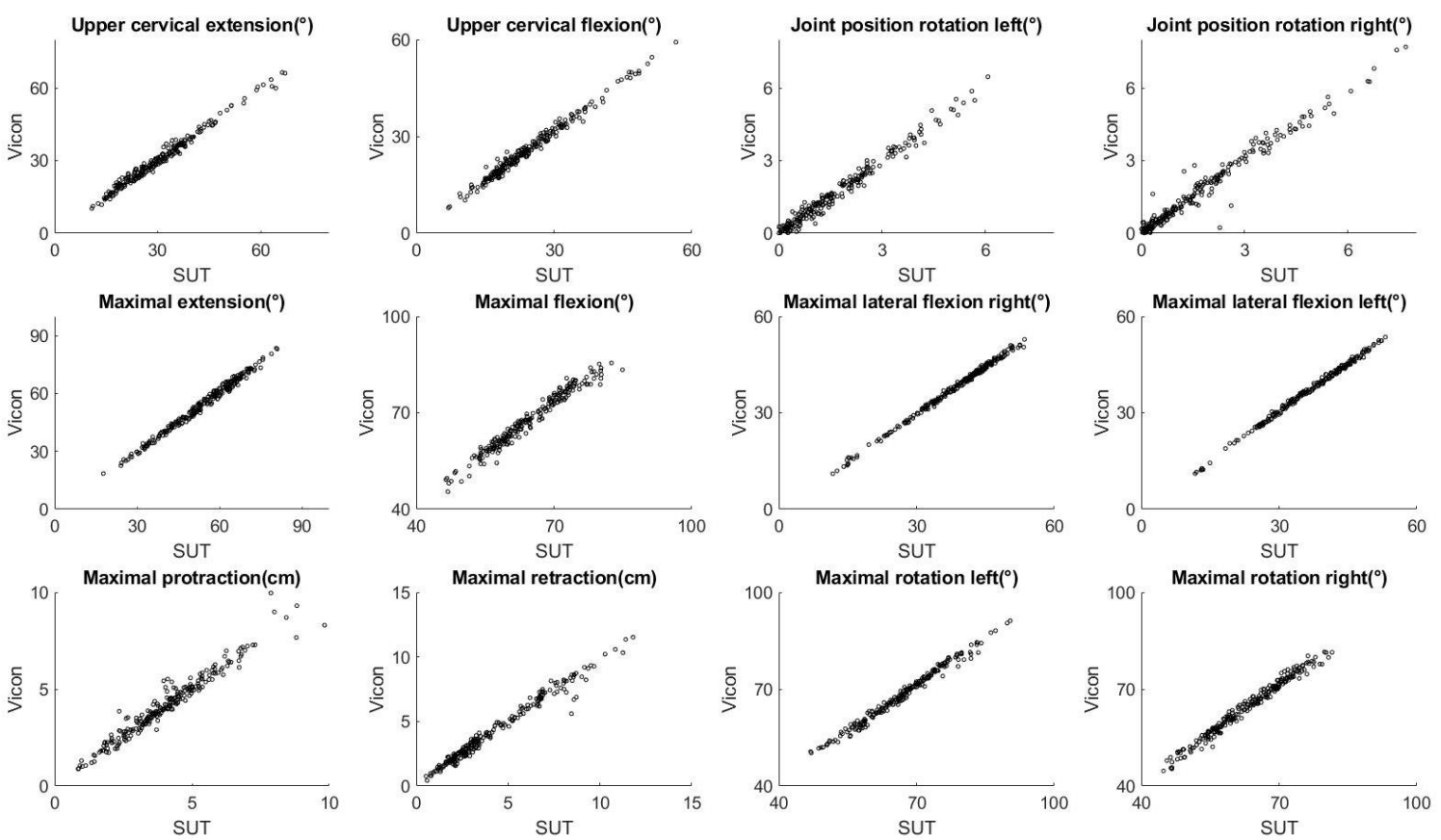


\section{Figure 3}

\section{Maximal flexion}
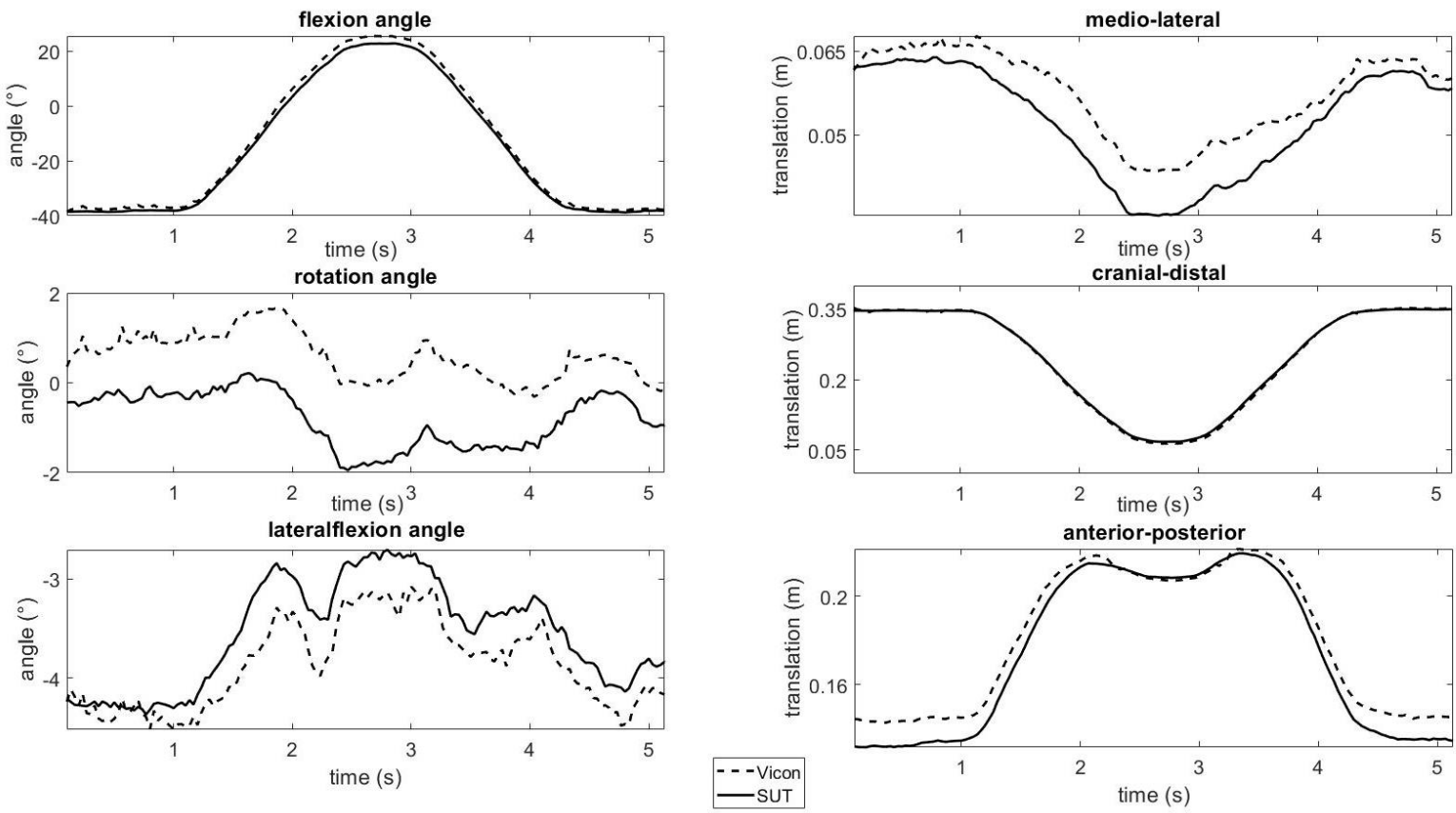
Table 3

\begin{tabular}{|c|c|c|c|c|c|c|}
\hline & \multicolumn{3}{|c|}{ Angular movement } & \multicolumn{3}{c|}{ Translation } \\
\cline { 2 - 7 } & $\begin{array}{c}\text { Lateral } \\
\text { flexion } \\
{\left[{ }^{\circ}\right]}\end{array}$ & Rotation & $\begin{array}{c}\text { Flexion / } \\
\text { extension } \\
{\left[{ }^{\circ}\right]}\end{array}$ & $\begin{array}{c}\text { Lateral }- \\
\text { medial } \\
{[\mathrm{cm}]}\end{array}$ & $\begin{array}{c}\text { Cranial }- \\
\text { caudal } \\
{[\mathrm{cm}]}\end{array}$ & $\begin{array}{c}\text { Anterior }- \\
\text { posterior } \\
{[\mathrm{cm}]}\end{array}$ \\
\hline UCEX & 1.1 & 1.9 & 2.0 & 0.4 & 0.6 & 0.4 \\
\hline UCFL & 1.0 & 1.7 & 1.9 & 0.4 & 0.5 & 0.3 \\
\hline JPRL & 1.1 & 2.1 & 2.0 & 0.4 & 0.5 & 0.4 \\
\hline JPRR & 1.5 & 1.9 & 2.2 & 0.4 & 0.7 & 0.4 \\
\hline MEXT & 1.2 & 2.0 & 2.0 & 0.6 & 0.7 & 0.4 \\
\hline MFLX & 1.0 & 1.7 & 1.6 & 0.8 & 0.4 & 0.4 \\
\hline MLFR & 1.0 & 1.8 & 1.7 & 0.5 & 0.5 & 0.5 \\
\hline MLFL & 1.0 & 1.8 & 2.9 & 0.4 & 0.4 & 0.5 \\
\hline MPRT & 1.1 & 1.8 & 2.2 & 0.4 & 0.5 & 0.4 \\
\hline MRET & 1.0 & 1.8 & 2.3 & 0.4 & 0.5 & 0.5 \\
\hline MROL & 1.5 & 2.5 & 2.0 & 0.4 & 0.5 & 0.5 \\
\hline MROR & 3.1 & 1.7 & 2.9 & 0.4 & 0.9 & 0.4 \\
\hline ZIZA & 0.2 & 0.4 & 0.8 & 0.2 & 0.2 & 0.1 \\
\hline
\end{tabular}


Table 4

\begin{tabular}{|c|c|c|c|c|c|c|c|c|}
\hline & $\begin{array}{c}\text { Instrum } \\
\text { ent }\end{array}$ & $\begin{array}{l}\text { Mean } \\
\text { ROM } \\
{\left[{ }^{\circ}, \mathrm{cm}\right]}\end{array}$ & $\begin{array}{c}\text { SD } \\
\text { ROM } \\
{\left[{ }^{\circ}, \mathrm{cm}\right]}\end{array}$ & $\begin{array}{l}\sigma_{p}^{2} \\
{[\%]}\end{array}$ & $\begin{array}{c}\sigma_{p d}^{2} \\
{[\%]}\end{array}$ & $\begin{array}{c}\sigma_{p r d}^{2} \\
{[\%]}\end{array}$ & $\begin{array}{c}\text { repetitio } \\
\text { ns } \\
\text { required } \\
\text { for } \Phi> \\
0.75\end{array}$ & $\begin{array}{c}\text { repetitio } \\
\text { ns } \\
\text { required } \\
\text { for } \Phi> \\
0.4\end{array}$ \\
\hline \multirow{2}{*}{ UCEX } & SUT & 29.9 & 10.7 & 69.3 & 18.8 & 7.6 & 5 & 1 \\
\hline & Vicon & 29.9 & 10.5 & 66.8 & 19.9 & 8.6 & $>7$ & 1 \\
\hline \multirow{2}{*}{ UCFL } & SUT & 24.4 & 8.6 & 33.2 & 50.4 & 12.9 & $>7$ & $>7$ \\
\hline & Vicon & 26.0 & 8.9 & 35.8 & 48.3 & 11.5 & $>7$ & 4 \\
\hline \multirow{2}{*}{ MEXT } & SUT & 53.3 & 12.9 & 70.8 & 18.4 & 10.2 & 3 & 1 \\
\hline & Vicon & 53.6 & 13.5 & 71.1 & 17.8 & 9.9 & 3 & 1 \\
\hline \multirow{2}{*}{ MFLX } & SUT & 64.5 & 8.2 & 71.7 & 14.7 & 8.8 & 2 & 1 \\
\hline & Vicon & 67.5 & 8.8 & 70.6 & 17.1 & 8.2 & 3 & 1 \\
\hline \multirow{2}{*}{ MLFR } & SUT & 38.3 & 9.1 & 86.9 & 6.0 & 6.4 & 1 & 1 \\
\hline & Vicon & 37.7 & 8.9 & 87.0 & 6.0 & 6.3 & 1 & 1 \\
\hline \multirow{2}{*}{ MLFL } & SUT & 36.6 & 8.7 & 85.8 & 6.9 & 4.9 & 1 & 1 \\
\hline & Vicon & 37.0 & 8.8 & 84.8 & 8.2 & 4.7 & 1 & 1 \\
\hline \multirow{2}{*}{ JPRL } & SUT & 1.7 & 1.4 & 12.5 & 3.3 & 71.4 & $>7$ & 6 \\
\hline & Vicon & 1.7 & 1.4 & 14.9 & 5.3 & 67.6 & $>7$ & 5 \\
\hline \multirow{2}{*}{ JPRR } & SUT & 1.8 & 1.6 & 40.4 & 7.0 & 52.6 & $>7$ & 1 \\
\hline & Vicon & 1.8 & 1.6 & 40.7 & 6.0 & 53.3 & $>7$ & 1 \\
\hline \multirow{2}{*}{ MROL } & SUT & 67.0 & 8.7 & 64.0 & 18.7 & 8.7 & $>7$ & 1 \\
\hline & Vicon & 68.4 & 8.5 & 63.8 & 19.0 & 8.9 & $>7$ & 1 \\
\hline \multirow{2}{*}{ MROR } & SUT & 63.1 & 8.5 & 66.5 & 21.8 & 9.0 & $>7$ & 1 \\
\hline & Vicon & 64.5 & 8.7 & 66.6 & 21.2 & 9.2 & $>7$ & 1 \\
\hline \multirow{2}{*}{ MPRT } & SUT & 4.0 & 1.8 & 66.0 & 13.8 & 18.3 & 3 & 1 \\
\hline & Vicon & 4.2 & 1.9 & 67.7 & 13.6 & 16.4 & 3 & 1 \\
\hline \multirow{2}{*}{ MRET } & SUT & 4.2 & 2.6 & 72.1 & 11.7 & 15.3 & 2 & 1 \\
\hline & Vicon & 4.2 & 2.5 & 73.6 & 10.0 & 16.0 & 2 & 1 \\
\hline
\end{tabular}


Table 5

\begin{tabular}{|c|c|c|c|}
\hline & $\begin{array}{c}\sigma_{p}^{2} \\
{[\%]}\end{array}$ & $\begin{array}{c}\sigma_{p d}^{2} \\
{[\%]}\end{array}$ & $\begin{array}{c}\sigma_{\text {prd }}^{2} \\
{[\%]}\end{array}$ \\
\hline UCEX & 0.0 & 95.3 & 4.7 \\
\hline UCFL & 0.0 & 95.5 & 4.0 \\
\hline JPRL & 14.6 & 80.9 & 3.5 \\
\hline JPRR & 20.3 & 72.2 & 4.8 \\
\hline MEXT & 0.0 & 95.1 & 4.8 \\
\hline MFLX & 0.0 & 92.1 & 7.9 \\
\hline MLFR & 34.6 & 56.5 & 8.1 \\
\hline MLFL & 48.0 & 35.1 & 8.5 \\
\hline MPRT & 41.8 & 36.4 & 16.1 \\
\hline MRET & 44.0 & 41.2 & 14.7 \\
\hline MROL & 11.1 & 85.6 & 2.3 \\
\hline MROR & 31.8 & 66.2 & 2.0 \\
\hline ZIZA & 18.0 & 17.1 & 62.7 \\
\hline
\end{tabular}




\section{References}

Audette, I., Dumas, J.-P., Côté, J.N., De Serres, S.J., 2010. Validity and Between-Day Reliability of the Cervical Range of Motion (CROM) Device. J. Orthop. Sports Phys. Ther. 40, 318-323. doi:10.2519/jospt.2010.3180

Bates, D., Maechler, M., Bolker, B., Walker, S., 2015. Fitting Linear Mixed-Effects Models Using Ime4. J. Stat. Softw. 67, 1-48. doi:10.18637/jss.v067.i01

Brennan, R.L., 2001. Generalizability Theory (Statistics for Social and Behavioral Sciences). SpringerVerlag, New York.

Childs, J.D., Cleland, J.A., Elliott, J.M., Teyhen, D.S., Wainner, R.S., Whitman, J.M., Sopky, B.J., Godges, J.J., Flynn, T.W., Delitto, A., Dyriw, G.M., Ferland, A., Fearon, H., MacDermid, J., Matheson, J.W., McClure, P., Shekelle, P., Smith, A.R., Torburn, L., 2008. Neck Pain: Clinical Practice Guidelines Linked to the International Classification of Functioning, Disability, and Health From the Orthopaedic Section of the American Physical Therapy Association. J. Orthop. Sports Phys. Ther. 38, A1-A34. doi:10.2519/jospt.2008.0303

Ernst, M.J., Crawford, R.J., Schelldorfer, S., Rausch-Osthoff, A.-K., Barbero, M., Kool, J., Bauer, C.M., 2015. Extension and flexion in the upper cervical spine in neck pain patients. Man. Ther. 20, 547-552. doi:10.1016/j.math.2014.12.005

Hall, T.M., Briffa, K., Hopper, D., Robinson, K.W., 2010. The relationship between cervicogenic headache and impairment determined by the flexion-rotation test. J Manip. Physiol Ther 33, 666-71. doi:10.1016/j.jmpt.2010.09.002

Jørgensen, R., Ris, I., Falla, D., Juul-Kristensen, B., 2014. Reliability, construct and discriminative validity of clinical testing in subjects with and without chronic neck pain. BMC Musculoskelet. Disord. 15, 408.

Lee, H., Nicholson, L.L., Adams, R.D., 2005. Neck Muscle Endurance, Self-Report, and Range of Motion Data From Subjects With Treated and Untreated Neck Pain. J. Manipulative Physiol. Ther. 28, 25-32. doi:10.1016/j.jmpt.2004.12.005

Lee, H.-Y., Teng, C.-C., Chai, H.-M., Wang, S.-F., 2006. Test-retest reliability of cervicocephalic kinesthetic sensibility in three cardinal planes. Man. Ther. 11, 61-68. doi:10.1016/j.math.2005.03.008

Liu, H., Shah, S., Jiang, W., 2004. On-line outlier detection and data cleaning. Comput. Chem. Eng. 28, 1635-1647. doi:10.1016/j.compchemeng.2004.01.009

Niehorster, D.C., Li, L., Lappe, M., 2017. The Accuracy and Precision of Position and Orientation Tracking in the HTC Vive Virtual Reality System for Scientific Research. -Percept. 8, 204166951770820. doi:10.1177/2041669517708205

Ordway, N.R., Seymour, R., Donelson, R.G., Hojnowski, L., Lee, E., Edwards, W.T., 1997. Cervical sagittal range-of-motion analysis using three methods. Cervical range-of-motion device, 3space, and radiography. Spine Phila Pa 1976 22, 501-8.

Park, S.H., 2015. Kinematic analysis of the lower cervical spine in the protracted and retracted neck flexion positions. J. Phys. Ther. Sci. 27, 135-137.

R Core Team, 2018. , R: A language and environment for statistical computing. R Foundation for Statistical Computing, Vienna, Austria.

Santos, B.R., Delisle, A., Larivière, C., Plamondon, A., Imbeau, D., 2008. Reliability of centre of pressure summary measures of postural steadiness in healthy young adults. Gait Posture 27, 408-415. doi:10.1016/j.gaitpost.2007.05.008

Seo, S.H., Hwang-Bo, G., Yuk, G.-C., Han, J.-T., Kim, J.-H., Park, S.H., 2013. Dynamic Intervertebral Body Angle of the Lower Cervical Spine during Protracted Head Extension Using Measured by Fluoroscopy. J. Phys. Ther. Sci. 25, 237-239. 
Severinsson, Y., Elisson, L., Bunketorp, O., 2012. Reliability of Measuring the Cervical Sagittal Translation Mobility with a Simple Method in a Clinical Setting. Rehabil. Res. Pract. 2012, 19. doi:10.1155/2012/629104

Stemper, B.D., Yoganandan, N., Pintar, F.A., 2006. Effect of head restraint backset on head-neck kinematics in whiplash. Accid. Anal. Prev. 38, 317-323. doi:10.1016/j.aap.2005.10.005

Treleaven, J., Jull, G., Sterling, M., 2003. Dizziness And Unsteadiness Following Whiplash Injury: Characteristic Features And Relationship With Cervical Joint Position Error. J. Rehabil. Med. 35, 36-43. doi:10.1080/16501970306109

Vernon, H., 2008. The Neck Disability Index: State-of-the-Art, 1991-2008. J. Manipulative Physiol. Ther. 31, 491-502. doi:10.1016/j.jmpt.2008.08.006

Wang, J., Hsu, Y., Liu, J., 2010. An Inertial-Measurement-Unit-Based Pen With a Trajectory Reconstruction Algorithm and Its Applications. IEEE Trans. Ind. Electron. 57, 3508-3521. doi:10.1109/TIE.2009.2038339

Werner, I.M., Ernst, M.J., Treleaven, J., Crawford, R.J., 2018. Intra and interrater reliability and clinical feasibility of a simple measure of cervical movement sense in patients with neck pain. BMC Musculoskelet. Disord. 19. doi:10.1186/s12891-018-2287-0 